\title{
Radiochromic Films for the Two-Dimensional Dose Distribution Assessment
}

\author{
Pierluigi Casolaro
}

Citation: Casolaro, P. Radiochromic Films for the Two-Dimensional Dose Distribution Assessment. Appl. Sci. 2021, 11, 2132. https://doi.org/ 10.3390/app11052132

Academic Editor: Antonio Di Bartolomeo

Received: 17 January 2021

Accepted: 23 February 2021

Published: 28 February 2021

Publisher's Note: MDPI stays neutral with regard to jurisdictional claims in published maps and institutional affiliations.

Copyright: (C) 2021 by the author. Licensee MDPI, Basel, Switzerland. This article is an open access article distributed under the terms and conditions of the Creative Commons Attribution (CC BY) license (https:// creativecommons.org/licenses/by/ $4.0 /)$.
Albert Einstein Center for Fundamental Physics (AEC), Laboratory for High Energy Physics (LHEP), University of Bern, Sidlerstrasse 5, CH-3012 Bern, Switzerland; pierlugi.casolaro@lhep.unibe.ch

\begin{abstract}
Radiochromic films are mainly used for two-dimensional dose verification in photon, electron, and proton therapy treatments. Moreover, the radiochromic film types available today allow their use in a wide dose range, corresponding to applications from low-medical diagnostics to high-dose beam profile measurements in charged particle medical accelerators. An in-depth knowledge of the characteristics of radiochromic films, of their operating principles, and of the dose reading techniques is of paramount importance to exploit all the features of this interesting and versatile radiation detection system. This short review focuses on these main aspects by considering the most recent works on the subject.
\end{abstract}

Keywords: radiochromic film; beam profile measurement; beam diagnostics; radiation detection; dosimetry; radiation therapy

\section{Introduction}

Accurate knowledge of the characteristics of the radiation field is crucial in medical applications of particle physics. As an example, medical cyclotrons, either for hadrontherapy or for radioisotope production, are equipped with beam instrumentation and detection systems to assure effective cancer treatments, as well as functional and safe production. Ionization chambers and Faraday Cups are usually installed in beam lines to measure the beam current. Beam profiles are measured by means of beam viewers, plastic scintillators, optical fiber-based detectors, scintillation screens, and secondary electron emission detectors [1-7].

High resolution two-dimensional measurements of the dose distribution can be achieved with radiochromic films (RCFs). These instruments are mainly used in the dose verification and quality assurance in radiation therapy with photon, electron and proton beams [8-11]. The remarkable interest of the scientific community to RCF dosimetry is confirmed by the high number of publications on this topic. By the end of 2015, nearly 1000 papers on RCFs have been published on peer-reviewed journals with a growing trend [12]. Several comprehensive works, including reviews and protocols, as well as a book on RCF dosimetry, have been published so far [12-18]. Such a wide use is due to the number of their unique features compared to other detectors and dosimeters. The main strengths are the sub-millimeter spatial resolution, near water-equivalence, sensitivity to many radiation types and to a wide dose range, weak dependency on the energy, and dose rate. In addition, the relative ease of use and cost are considerable advantages. The first radiochromic materials were developed to be used only in high dose applications, such as radiation processing, including sterilization of food and medical devices [19,20]. Successively, new radiochromic media were developed with an improved sensitivity to doses of medical interest $[21,22]$. Today, many RCF types are available, covering a sensitivity dose range from a few $\mathrm{mGy}$ to hundreds of $\mathrm{kGy}$; this allows their use in applications from the low dose radiological diagnostic to Quality Assurance (QA) in radiotherapy, brachytherapy up to high dose radiation processing [23-26]. Because of this versatility and of the aforementioned characteristics, RCFs are used in applications for which an in-depth characterization 
of the particle beam profile and homogeneity is required, such as in the monitoring of the irradiation for radiation hardness [27-31], as well as in the characterization of charged particle beam lines for radiobiology studies [32-35]. RCFs are used in the dosimetric characterization of proton and heavy ion beams for hadron-therapy [36-39]. Beam profile measurements with RCFs are performed at cyclotrons for radioisotope production mainly for guaranteeing the beam positioning on target materials [40,41]. As an example, RCFs are used for this purpose, as well as for the accurate beam characterization in studies of the radiation damage for high energy physics and spatial applications at the $18 \mathrm{MeV}$ cyclotron in operation at the Bern University Hospital (Inselspital) [31,42,43]. The independence of RCFs on the dose rate resulted in their application in ultra-high dose beam diagnostics studies, such as laser-plasma proton beams and FLASH radiotherapy [44-47]. In addition to the conventional two-dimensional dose distribution measurements, stacks of RCFs have been successfully used to measure energy spectra in these challenging applications [48].

In order to exploit all the features of this interesting radiation detector, an in-depth knowledge of its main features is necessary. The use of a specific reading technique allows, e.g., measurements in dynamic and sensitivity ranges other than those obtained by using another reading technique. This review discusses the main characteristics of RCFs, with the aim of shed light on their use as a useful radiation detector in all the applications in which the in-depth characterization of the radiation field (both charged particle, electron, and photon) is required. In order to point out these aspects, several RCF models and reading techniques are discussed in this work. Section 2, in particular, reports on the basics of RCFs and on their operating principles, as well as on the physical quantities used for their reading. Section 3 presents the main RCFs reading techniques. Section 4 discusses on the main dependence on relevant physical quantities with a focus on the radiation type and energy. Conclusions and outlook are drawn in Section 4.

\section{Basics of Radiochromic Films}

\subsection{Operating Principle and Formation of the Image}

$\mathrm{RCFs}$ exhibit a progressive coloration when exposed to ionizing radiation. Their degree of coloration is a strictly monotone function of the absorbed dose. As a consequence of this, one can determine a calibration equation which relates the grade of coloration to the absorbed dose. The calibration equation is therefore used to measure unknown doses. Most of the RCFs available today feature the organic compound of diacetylene (a type of crystalline polyacetylene) as the material responsible for the coloration [49]. Its exposure to ionizing radiation triggers the solid-state polymerization reaction with formation of colored polymer chains. The dyacetilene monomers are bound in gel in the form of crystalline dispersion which is coated on one or more thin transparent polyester bases [50]. The different RCF types differ from each other for the chemical composition and size of the sensitive element, as well as of the plastic support. The considerable advantage of RCFs with respect to silver halide films is in the kinetics of the chemical processes. Silver halide films feature a latent image which can further develop in the form of a photograph by means of the chemical processes of fixing and rinsing. RCFs are self-developing and the primary image is formed almost instantaneously. Studies on the kinetics of the RCF reaction were carried out by Mc Laughin et al. in 1996 for two RCF models which are no more in use, i.e., Gafchromic ${ }^{\mathrm{TM}}$ DM 1260 and Gafchromic ${ }^{\mathrm{TM}}$ MD 55 (ISP Technologies, Inc., Waterford, MI, USA) [51]. They reported on changes in relative absorbance, observed with a spectrophotometer, at the wavelength $675 \mathrm{~nm}$ following a $50 \mathrm{~ns}, 20$ Gy electron pulse. Moreover, they demonstrated that the primary image formation terminates after $2 \mathrm{~ms}$ and the entire polymerization reaction continues after the irradiation is ceased. Cheung et al. reported a percentage variation in Gafchromic ${ }^{\mathrm{TM}}$ EBT (which stands for "External Beam Therapy") up to $9 \%$ within the first $12 \mathrm{~h}$ after $1 \mathrm{~Gy}$ irradiation [52]. EBT-3 Gafchromic ${ }^{\mathrm{TM}}$ films have been found to change their darkening up to $4 \%$ in $4 \mathrm{~h}$ following a 20 Gy electron irradiation [53]. For convenience, most of the recent works and protocols on RCF dosimetry recommend a $24 \mathrm{~h}$ gap between the end of the irradiation and its analysis. 


\subsection{Radiochromic Film Types}

The RCF types differ from each other for their own structural characteristics, such as active layer's or substrate's composition and size, resulting in different sensitivity to the radiation dose, type, and energy. Gafchromic ${ }^{\mathrm{TM}}$ films are designed to be used in specific applications of medical radiology and radiotherapy. However, thanks to their versatility, they are commonly used also in other domains of the radiation physics. The Gafchromic ${ }^{\mathrm{TM}} \mathrm{XR}$ models are sensitive in the dose range 0.1-20 cGy and are designed for Quality Assurance (QA) radiology tests (XR-QA2), for measurements on CT scanners (XR$\mathrm{CT} 2)$, for mammography QA tests (XR-M2), and for surface dose measurements (XR-RV3) in procedures guided by fluoroscopy [54-56]. Gafchromic ${ }^{\mathrm{TM}} \mathrm{EBT}$ models are particularly suited for measurements in high energy photon fields and therefore in Intensity Modulated Radiation Therapy (IMRT), Volumetric Modulated Arc Therapy (VMAT), Stereotactic radiosurgery (STR), and Stereotactic body radiation therapy (SBRT) applications $[24,57]$. The structure and dynamic range of these RCF types and of the one mentioned below is shown in Figure 1.

\begin{tabular}{|c|} 
Gafchromic $^{\mathrm{TM}}$ XRQA-2 $[0.1-20 \mathrm{cGy}]$ \\
Yellow Polyester $(97 \mu \mathrm{m})$ \\
Adhesive Layer $(20 \mu \mathrm{m})$ \\
Active Layer $(25 \mu \mathrm{m})$ \\
Polyester $(97 \mu \mathrm{m})$ \\
\hline
\end{tabular}
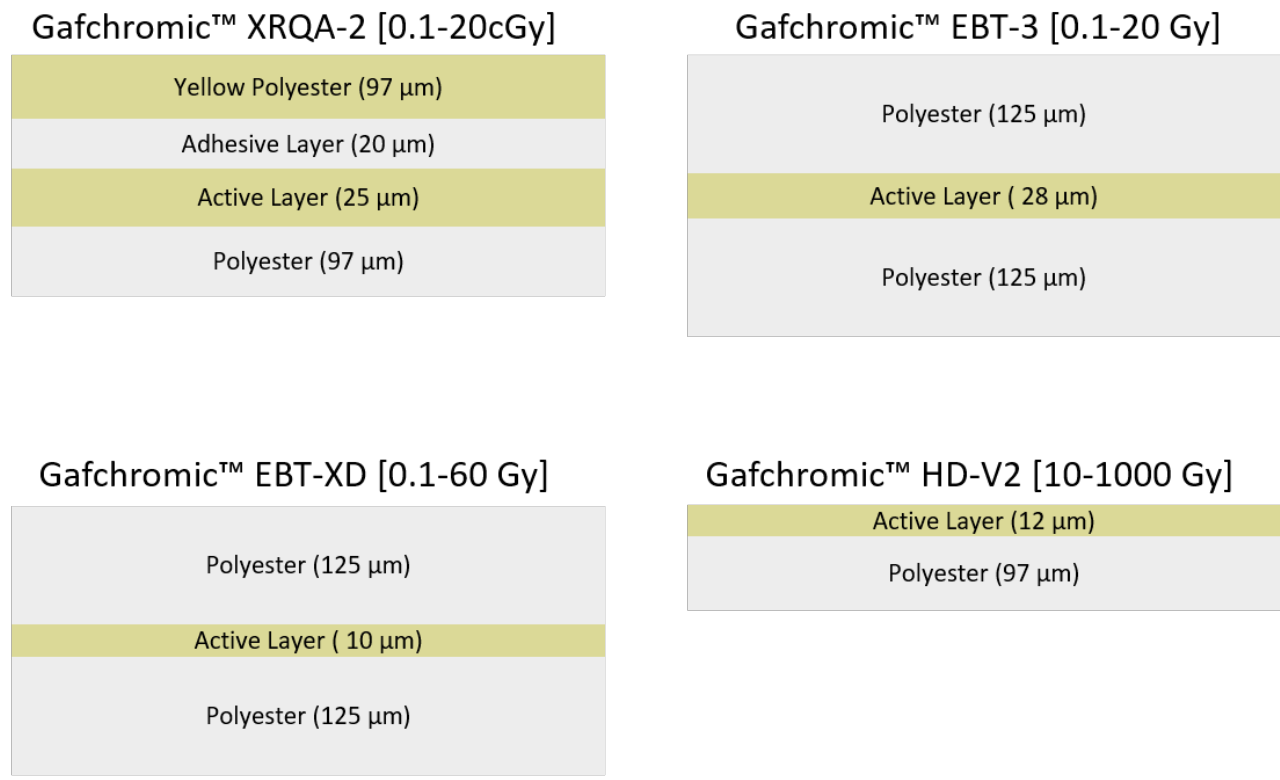

$$
\begin{gathered}
\text { B3 films [0.5-200 kGy] } \\
\text { B3 film } 18 \mu \mathrm{m}
\end{gathered}
$$

FWT-60 films [0.5-200 kGy]

FWT-60-00 film $(42-52 \mu \mathrm{m})$

Figure 1. Structure and dynamic range of some radiochromic film (RCF) types.

The EBT models available today are the EBT-3, sensitive in the dynamic range 0.1-20 Gy and EBT-XD, featuring extended dynamics up to $60 \mathrm{~Gy}$. Gafchromic ${ }^{\mathrm{TM}} \mathrm{MD}-$ V3 (dynamic range 1-100 Gy) and HD-V2 (dynamic range 10-1000 Gy) are available for higher doses. According to the manufacturer, these films have a spatial resolution of less than $25 \mu \mathrm{m}$. They are made of one or more polyester substrates, an adhesive layer (present only in some models), lithium pentacosa-10,12-diynoate (LiPCDA) as active layer, and other elements in fraction of the order of 1\% [16]. Thin film dosimeters are available for high dose applications, such as radiation processing. Gex Corporation trades B3 RCFs for application in the high dose range from a few hundred Gy to more than $150 \mathrm{kGy}$ [58]. B3 RCFs feature $18 \mu \mathrm{m}$ (nominal thickness) polyvinyl butyral (PVB) resin with the addition of pararosaniline as a radiochromic dye. FWT-60 RCFs are traded by Far West Technology, Inc. Goleta, CA, United States. They feature the hexa(hydroxyethyl) aminotriphenylacetonitrile (HHEVC) as a dye and are sensitive in the range 0.5-200 kGy [59]. The information on the 
structure and the dynamic range of these RCFs was found in the specification guidelines reported on the manufacturer's website [60]. It should be noted that RCF models of a specified dynamic range could be used beyond the mentioned range at the expense of a reduced measurement sensitivity. This is consequence of the fact the RCF response is not linear with the dose; moreover, the dynamic range and sensitivity depends on the data analysis technique.

\subsection{Physical Quantities for Measuring the Radiochromic Film Darkening}

The exposure of RCFs to a defined radiation dose provokes darkening which can be related to the absorbed dose; thus, the darkening needs to be quantitatively measured. The physical quantity used for this purpose can be defined on the basis of the characteristics of either the RCF type or of the reading instrument. The interaction of the light with a thin film, such as an RCF, is a complex physical phenomenon which has been explained by Fusi et al. [61]. Referring to the schematics of Figure 2b, the light intensity interacting with the RCF has three main components:

1. transmitted (I) through the RCF and collected by the detector,

2. scattered $\left(I_{s}\right)$ by the RCF and not collected by the detector,

3. absorbed $\left(I_{a b s}\right)$ by the RCF.

a)

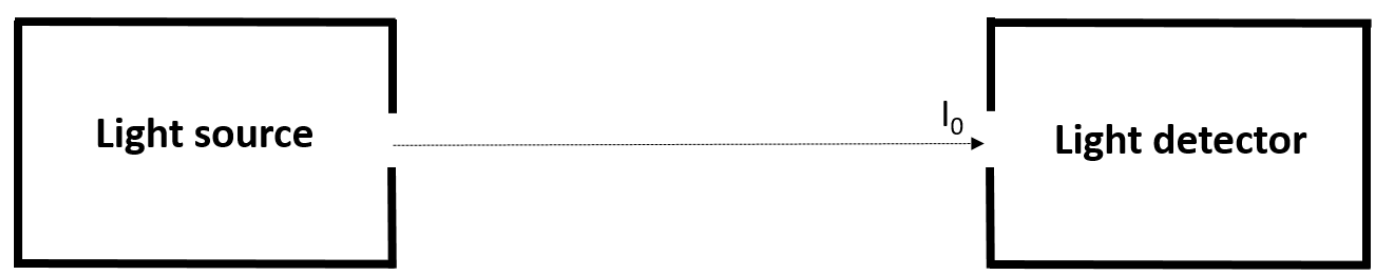

b)

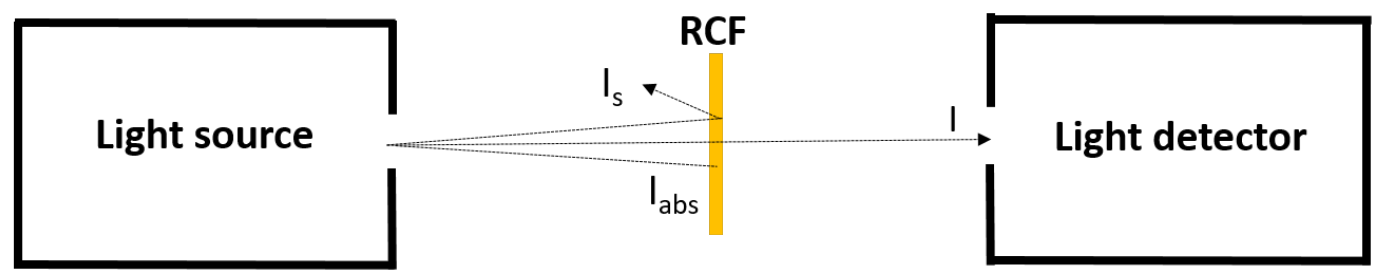

Figure 2. Schematics Please, note that I've uploaded a new version of figure 2 of improved quality (in particular some unwanted lines have been removed). showing the principle of measurement of the RCF darkening. $I_{0}$ denotes the light intensity detected without RCF (a); $I_{S}, I_{a b s}$ and I denote the components of light scattered, absorbed and transmitted respectively, by the RCF (b).

Here, the basic definition of transmittance $T$, reflectance $R$, and optical density $O D$ (or absorbance $A$ ) are recalled. Let $I_{0}$ be the light intensity detected from the light detector in absence of the RCF (see Figure 2a); thus, the transmittance is defined as the ratio

$$
T=I_{0} / I,
$$

the reflectance as the inverse of the transmittance

$$
R=I / I_{0},
$$

and the optical density (or absorbance) as the logarithm of the transmittance, in formula:

$$
O D \equiv A=\log _{10} T=\log _{10}\left(I_{0} / I\right)
$$


These physical quantities are often not directly used for the reading of the RCF darkening. Firstly, most of the RCF reading instruments do not measure directly the component of light transmitted by the RCF but a combination of light transmitted and scattered. In the second place, as the aforementioned quantities are functions of the wavelength, or of specific wavelength range, care should be taken when these are considered. Furthermore, the RCF grade of darkening has to be put in relation to the change of light intensity of the RCF after the exposure to radiation and before it. The net optical density (netOD) is defined as:

$$
n e t O D=\log _{10} \frac{I_{\text {unexp }}-I_{b c k g}}{I_{\text {exp }}-I_{b c k g}},
$$

where $I_{\text {exp }}$ is the light intensity of the film exposed to radiation, $I_{\text {unexp }}$ is that of the film not exposed to radiation, and $I_{b c k g}$ is the light intensity collected by the detector in absence of light from the source. The net optical density considers all these aspects and is commonly used for the RCF reading. The net reflectance and net transmittance are defined in the same way. The net reflectance is used for the reading of RCFs having an opaque layer (e.g., Gafchromic $^{\text {TM }}$ XRQA-2 films) by setting the reading instrument, typically a flatbed scanner, in reflectance mode. Other physical quantities can be used on the basis of the reading instrument. Today, most widespread instruments for RCF reading are flatbed scanners. The digitized image is analyzed and the Pixel Value (PV) of a defined region of interest (ROI) is evaluated. The PV of the exposed film can be then normalized by the PV of the unexposed film and converted to OD or netOD. It has been proved by Aldelaijan et al. that the reflection scanning mode leads to higher sensitivity even for RCFs featuring transparent layers, such as EBT-3 Gafchromic ${ }^{\mathrm{TM}}$, at the cost of limiting the dose range and of a higher uncertainty in comparison to transmission scan-based response functions [62]. The same authors reported also that the normalized PV of RCFs scanned in transmission mode leads to linear response up to $11 \mathrm{~Gy}$. The reading of RCFs with flatbed scanners is overall a delicate topic, discussed in Section 3.1.

\section{Instruments for Dose Reading}

The instruments for the measurement of the RCF darkness (densitometers, spectrometers, flatbed scanners, etc.) are all equipped with a light source and a system of light detectors. Before performing effective reading measurements with RCFs, some precautions should be taken. The scanning process induces polarization effects on RCFs [63], implying a change in the response which is a function of their orientation on the flatbed scanner. The RCF behaves as a polarizer upon scanning because of the needle-like-shape of the RCF polymers [16]. A difference of up to $15 \%$ in the optical density response has been observed for HF Gafchromic ${ }^{\mathrm{TM}}$ films (discontinued) [63]. A variation up to $9 \%$ in net optical density has been observed for EBT-2 Gafchromic ${ }^{\mathrm{TM}}$ films [64], whereas the newest EBT-3 Gafchromic ${ }^{\text {TM }}$ films have shown to have a less difference up to $4.5 \%$ in net optical density between landscape and portrait orientation [10]. As a result, the orientation of the RCF pieces to measure must be kept fixed during the scanning. It is recommended to cut RCFs with sharp scissors or guillotine cutter and to handle them wearing gloves in order to avoid fingerprints. It is good practice to number all RCF pieces to be irradiated and further analyzed.

It is well-known that RCFs are sensitive to UV light, temperature changes and humidity [17]. EBT Gafchromic ${ }^{\mathrm{TM}}$ films have been successfully proved to operate as UV radiation meter with a reproducible color change during exposure [65]. Some RCF types, such as EBT-3 Gafchromic ${ }^{\mathrm{TM}}$ films can be immersed in water and used for measurements in water phantoms $[66,67]$. However, evidence suggest that the optical properties of the cover layer of EBT-3 Gafchromic ${ }^{\mathrm{TM}}$ films change as a result of the interaction with water; thus, it is recommended to build new calibration curve for specif measurements in water phantom [68]. The accuracy of the RCF measurement can be improved by using a control RCF piece which serves to take into account any change in color due to the environmental causes. However, the use of an RCF control piece should be considered as a trade-off between 
accuracy and uncertainty as its use can affect measurement uncertainties [69]. The two following subsections deal with the three main RCF reading instruments, namely flatbed scanners, densitomers, and detection systems (spectrophotometers and spectrometers) for the RCF spectral response.

\subsection{Flatbed Scanners}

Flatbed scanners for the analysis of RCFs are widely used, in particular in medical applications, for their several advantages over other techniques. Flatbed scanners feature either a fluorescent lamp or an LED (the latter can be found in the latest models) light source and a system of light detectors, which, in most cases, is based on Charge Coupled Device (CCD) technology. The digitization of the RCF allows high spatial resolution dosimetry measurements, as well as accurate studies of the beam profile and homogeneity. It should be noticed that flatbed scanners have not been developed for RCF measurements and therefore their use for this specific purpose is not trivial. Referred works about RCF dosimetry with flatbed scanner discuss these aspects, as well as the techniques to mitigate them. The main concepts are reported here.

The stability of the light source in flatbed scanners for measurements with RCFs is a source of uncertainty to be considered. Ferreira et al. studied the performance of the Epson Expression 10000XL scanner, featuring a xenon fluorescent lamp, for IMRT dosimetry measurements [70]. They concluded that this scanner has excellent reproducibility, if at least seven scans are done before its use. Lárraga-Gutiérrez et al. studied the performance of LED-based scanners, in particular of the Epson V800 scanner featuring a white LED light source [71]. They found that the reproducibility and long-term stability of LED-based scanners are slightly better than those of scanners using a fluorescent light source. They also found a non-uniform response (up to 9\%) in LED-based scanners greater than that in fluorescent-based scanners.

Flatbed scanners used for RCF measurements have proved to have a non-uniform response in the direction perpendicular to the scan direction [72,73]. The scanner response decreases as the distance of the scan's position from the scanner center increases. This effect, also referred to as lateral scan effect (or lateral response artifact) has been deeply studied in the literature and it can be mainly ascribed to the polarization of the light transmitted through the RCF, as it polarizes upon irradiation [63]. As a consequence of this, the lateral response artifact increases with the increase of the RCF level of darkening and, thus, with the dose. Contributions to the lateral response artifact come also from the scattering of the light with the RCF, variations in optical path, and cross talk, which is relevant only for small fields and high dose gradients [74]. For relatively small pieces of RCF, a cardboard centering mask can be used to further guarantee the reproducibility of the measurements, while corrections are needed for large RCF scanning. Lewis and Chan proposed a methodology to solve lateral scanning artifacts based on correlating the response of the RCF calibration curves at different lateral positions in the flatbed scanner by means of a two-point rescaling [75]. Multichannel techniques, which evaluate the dose according to the information from the three color channels RGB, have been proved to reduce these effects, as well as to improve the precision of the measurement [76,77].

Software for image analysis, such as ImageJ and MATLAB, are commonly used in combination with flatbed scanners to provide quantitative dose, as well as dose profile information. FilmQA Pro software from Ashland Inc. is specifically designed for Gafchromic ${ }^{\mathrm{TM}}$ film measurements in quality assurance (QA) medical applications and it uses a proprietary multichannel algorithm to remove non-dose contributions [78,79]. Howard et al. described the analysis procedures with both FilmQA Pro and ImageJ software, by achieving $\pm 2 \%$ accuracy with both software [80]. RisøScan is a software package based on LabView that can be used for analysis of Risø B3 and FWT RCFs, as well as for Gafchromic ${ }^{\mathrm{TM}}$ films [81,82]. In order to have the highest reproduction quality of the original image, it is saved in TIFF format and digitized without the options for color correction usually present in scanner software. 
The spatial resolution of a dosimetry system comprising of RCFs and flatbed-scanners is determined by the intrinsic spatial resolution of the RCF, as well as by the scanner spatial resolution. The user can select different scanning resolutions in units of dot per inch (DPI). Scanning resolutions of 1200 DPI $(0.02 \mathrm{~mm} /$ pixel $)$ are typical with modern flat-bed scanners. However, it should be noted that RCF images digitized at high resolution feature high noise and large uncertainties. In addition, the time to scan and process such large images increases with the increasing DPI. Asero et al. evaluated the actual spatial resolution of a scanner used for Gafchromic XR-QA2 films by means of the Modulation Transfer Function (MTF) method [83]. They found that values higher than 150 DPI $(0.17 \mathrm{~mm} /$ pixel $)$ do not give significantly improve the spatial resolution. Spatial resolutions of $<10 \mu \mathrm{m}$ in combination with small uncertainties can be achieved with reading techniques, such as the Confocal Raman Spectroscopy [84]. These studies are crucial for the precise dosimetry in small radiation fields or in regions with high dose gradients [85]. The study of the works in the literature suggests that the use of $72 \mathrm{dpi}(0.35 \mathrm{~mm} / \mathrm{pixel})$ or $127 \mathrm{dpi}(0.20 \mathrm{~mm} / \mathrm{pixel})$ in combination with 48-bit depth color (16 bit per color channel) are the most common options [16,77], although scanning at higher DPI is possible. The digitized image is then analyzed as a matrix of the spatial coordinates and of the Pixel Values (PVs). As an example, Figure 3 shows the two-dimensional dose profile of an RCF, in this case, an HD-V2 Gafchromic ${ }^{\mathrm{TM}}$ film exposed to $126 \mathrm{~Gy}$.

200

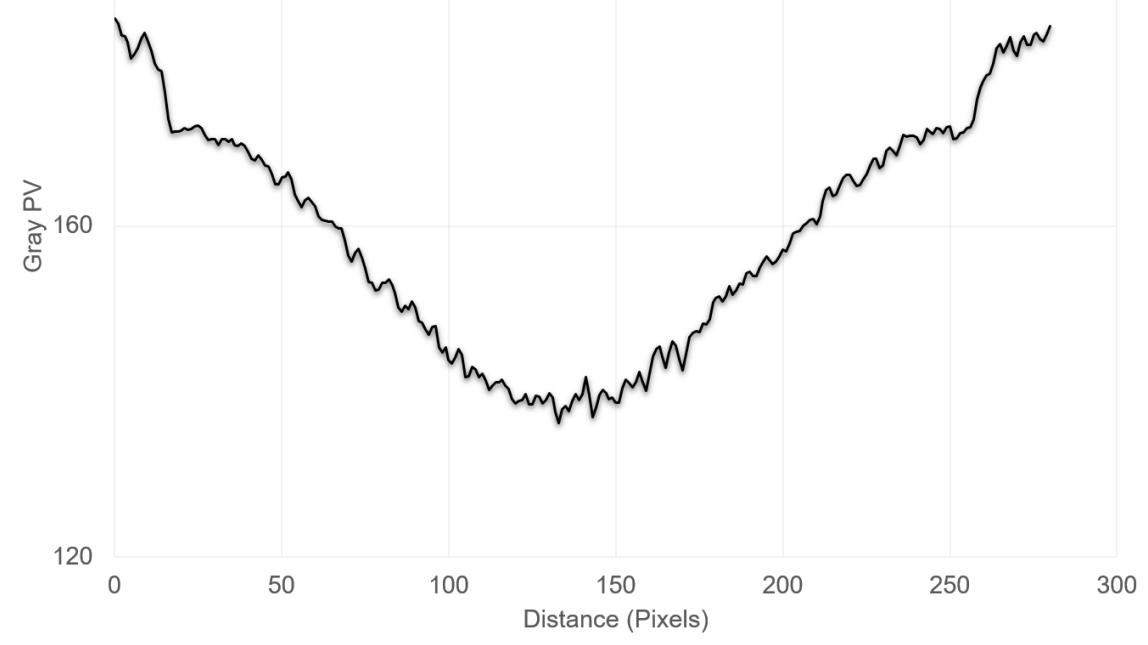

Figure 3. Typical two-dimensional dose distribution measured with RCFs. Adapted from Reference [86].

The gray PV is plotted as a function of the distance, expressed in pixels. It should be noted that in this scale 255 corresponds to the maximum light and 0 to no light transmission. The plot of Figure 3 shows the characteristic profile of the particular radiation field analyzed ( ${ }^{90} \mathrm{Sr} /{ }^{90} \mathrm{Y}$ beta source) featuring a $15 \times 15 \mathrm{~mm}^{2}$ square-shaped collimator. For dosimetry measurements, it is necessary to connect a dose value to a single piece of RCF, for example for calibration purposes. To this aim, a region of interest (ROI) is selected around the center of the irradiation of the digitized image, as shown in Figure $4 \mathrm{a}$.

From the histogram (Figure $4 \mathrm{~b}$ ) of the PVs of the selected ROIs, the average PV and its standard deviation are evaluated. The inset of Figure $4 \mathrm{~b}$ reports the statistical parameters of the selected ROI. On the same line, more than one ROIs can be selected and the average PV calculated as the average of the PVs of each ROI. For enhancing the accuracy of dosimetry measurements, the use of Wiener filter to further reduce the measurement uncertainties is recommended [87]. The RCF color image can be analyzed either in gray scale or RGB 
scale on the basis of the dynamic range and of the precision required for the specific measurement. Figure 5 shows the typical response of a set of Gafchromic ${ }^{\mathrm{TM}} \mathrm{HD}-\mathrm{V} 2$ films to different doses (up $1000 \mathrm{~Gy}$ ) as a function of the color channel.

a)

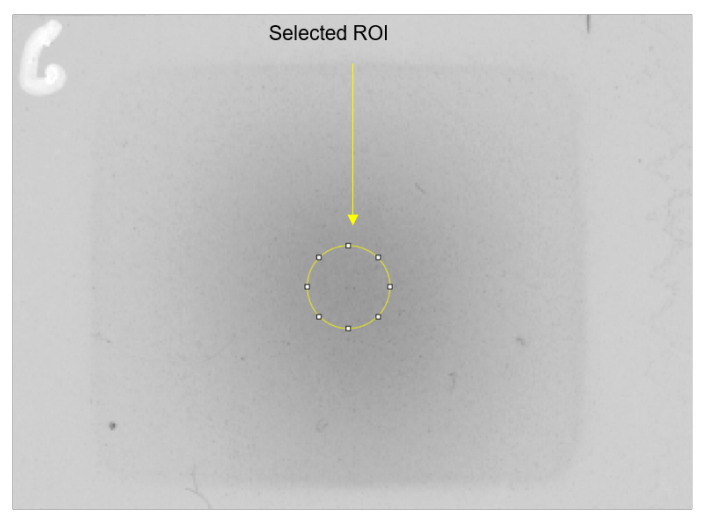

b)

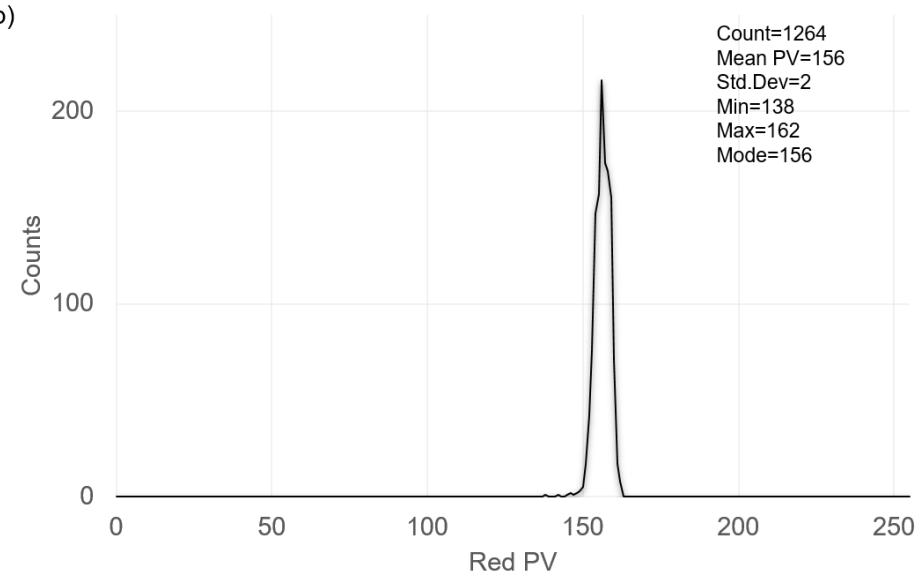

Figure 4. Selection of a region of interest (ROI) on an RCF (a) and corresponding histogram of the red Pixel Values (PVs) (b).

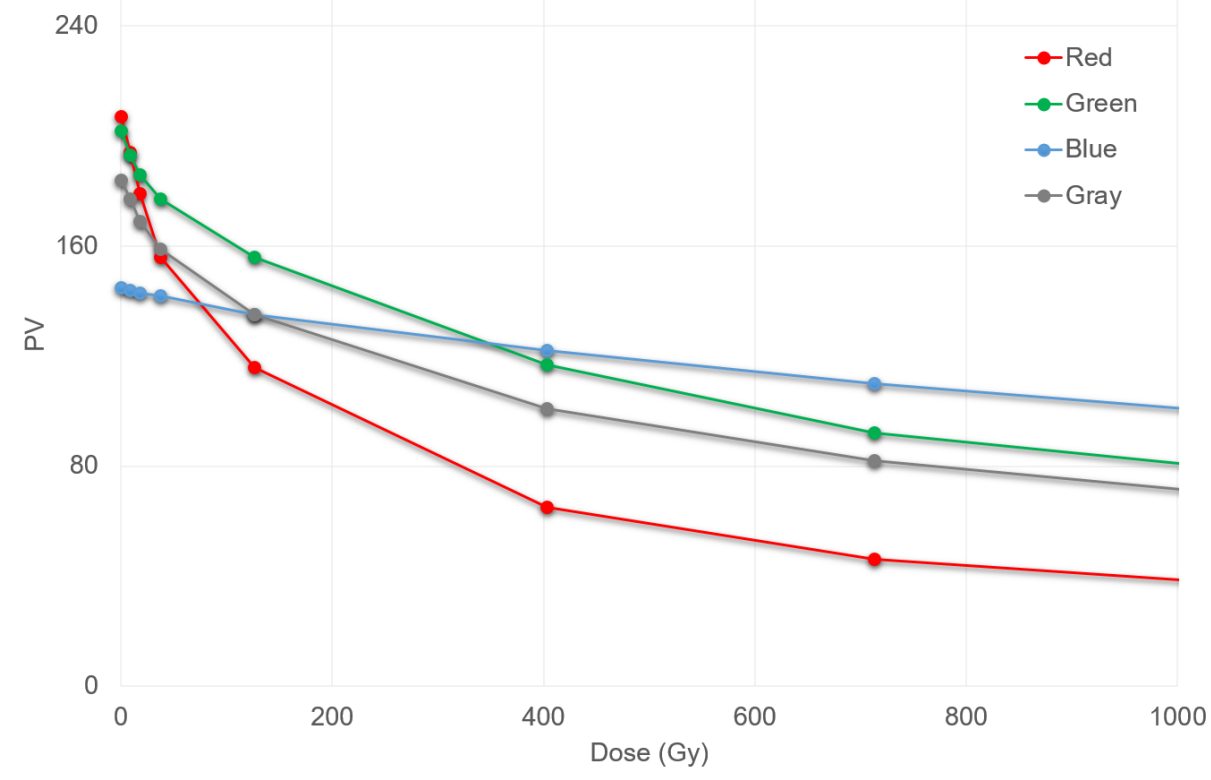

Figure 5. Response of the Gafchromic ${ }^{\mathrm{TM}} \mathrm{HD}-\mathrm{V} 2$ film to the different color channels.

Similar plots are reported from the manufacturer also for other Gafchromic ${ }^{\mathrm{TM}}$ films [60]. The red channel is better for discriminating low doses. The dynamic range can be increased by considering the green channel and (even more) the blue channel, at the cost of a loss of sensitivity. The gray PV has characteristics intermediate among the three color channels, with being $\mathrm{PV}_{\text {gray }}$ the average of the PVs of the other three channels:

$$
P V_{\text {gray }}=\frac{P V_{\text {red }}+P V_{\text {green }}+P V_{\text {blue }}}{3} .
$$

Once the dynamic range, the precision and the application field are defined, more than one choices are available for the calibration. This makes RCF dosimetry very flexible. Despite RCF calibration is discussed in this section, what follows is also valid for analysis methods other than flatbed scanners. Here, the main concepts behind the available options for the calibration are reported, while detailed procedures and functional equations can be found in the referred works. The calibration can be performed for one single color channel 
(or for one wavelength range), as well as by exploiting the information from the three RGB channels (or from more than one wavelength range) throughout multichannel methods. The strengths of multichannel methods rely on improving the accuracy of the measurement and reducing non-dose contributions, such as the lateral response artifacts [76]. An efficient flatbed-scanner-based protocol combining calibration and dose measurements (by IMRT and VMAT applications) in one single scan and that makes use of one reference film, one unexposed film and the exposed film has been reported by Lewis et al. [77]. Practically, the RCF calibration consists of exposing a set of RCFs from the same batch to known doses. The RCF dependence on the batch has been studied for different RCF and radiation types $[88,89]$. The batch dependence can be ascribed to slight differences in the chemical composition of the films and generally it increases at keV energies. Santos et al. have recently reviewed the most of the functional forms proposed so far for RCF calibration [18] These include rational, power, polynomial, and logarithmic functions, as well as universal functions applicable for several RCF types and dose ranges [90,91]. It should be noted that the choice of the calibration equation depends on the dynamic range and sensitivity required by the measurement as well as on the physical quantity used to evaluate the RCF darkening (netOD, raw PV, etc.).

\subsection{Densitometers and Spectrometers}

Densitometers provide direct measurement of the optical density (OD) of transparent films at fixed wavelengths. The OD calibration is usually verified with step tablets of known OD. Digital RCF readers are compact and easy-to-use instruments. In some cases, densitometers allow measurements for two wavelengths in order to provide two dynamic ranges. As an example, the Digital Radiochromic Reader Model FWT-92D, suited for the reading of high dose FWT-60 films, features incident light of two wavelengths (510 and $600 \mathrm{~nm}$ ) to cover the entire range of sensitivity [92]. RCF spectral response is an important piece of information for the analysis. To this aim, spectrophotometers have been used for the characterization of several RCF types to different radiation fields [93-95]. RCF spectral characterization has also been carried out by means of broadband spectrometers in combination with optical fibers $[88,89,96,97]$. As an example of this, Figure 6 shows the spectral response of EBT-3 Gafchromic ${ }^{\mathrm{TM}}$ film to several doses in the range 0-20 Gy.

The spectra of Figure 6 have been acquired by means of an opto-electronic system, of which a full description can be found in $[96,97]$. For the sake of clarity, its basic operation is summarized here. A light source sends light into an optical fiber transmission probe. The RCF is positioned between the end of the probe and a light-diffusive element, in this case, a Teflon cylinder. The incident light interacts with the RCF, and then it is backscattered by the Teflon cylinder and collected by an optical fiber which sends it to the spectrometer. Spectra of Figure 6 can be easily converted into optical density, according to Equation (1), as shown in Figure 7.

Spectra of Figures 6 and 7 show that the range of sensitivity of the RCF analyzed, in this case EBT3 Gafchromic ${ }^{\mathrm{TM}}$ film, is $500-700 \mathrm{~nm}$. The RCF which has not interacted with radiation has the highest intensity and optical density zero. The strengths of the approaches providing RCF spectral response rely on the possibility of defining optimal wavelength ranges for maximize the sensitivity or for extending the dynamic range in the RCF calibration. The evaluation of the intensity (or optical density) at fixed wavelength, as well as of the integral of the intensity (or that of the optical density) in a defined wavelength range, allows great versatility in the data analysis. The aforementioned opto-electronic system has been developed and optimized to operate in real time [97]. Indeed, standard techniques for the reading of the dose, such as flatbed scanners and densitometers, do not allow the dosimetry in real-time. On the contrary, optical fiber technology has proven to be effective to this purpose. On the same topic, real-time dosimetry systems with RCFs and optical fibers have been performed by Mignani et al. and Rink et al. [98,99]. 


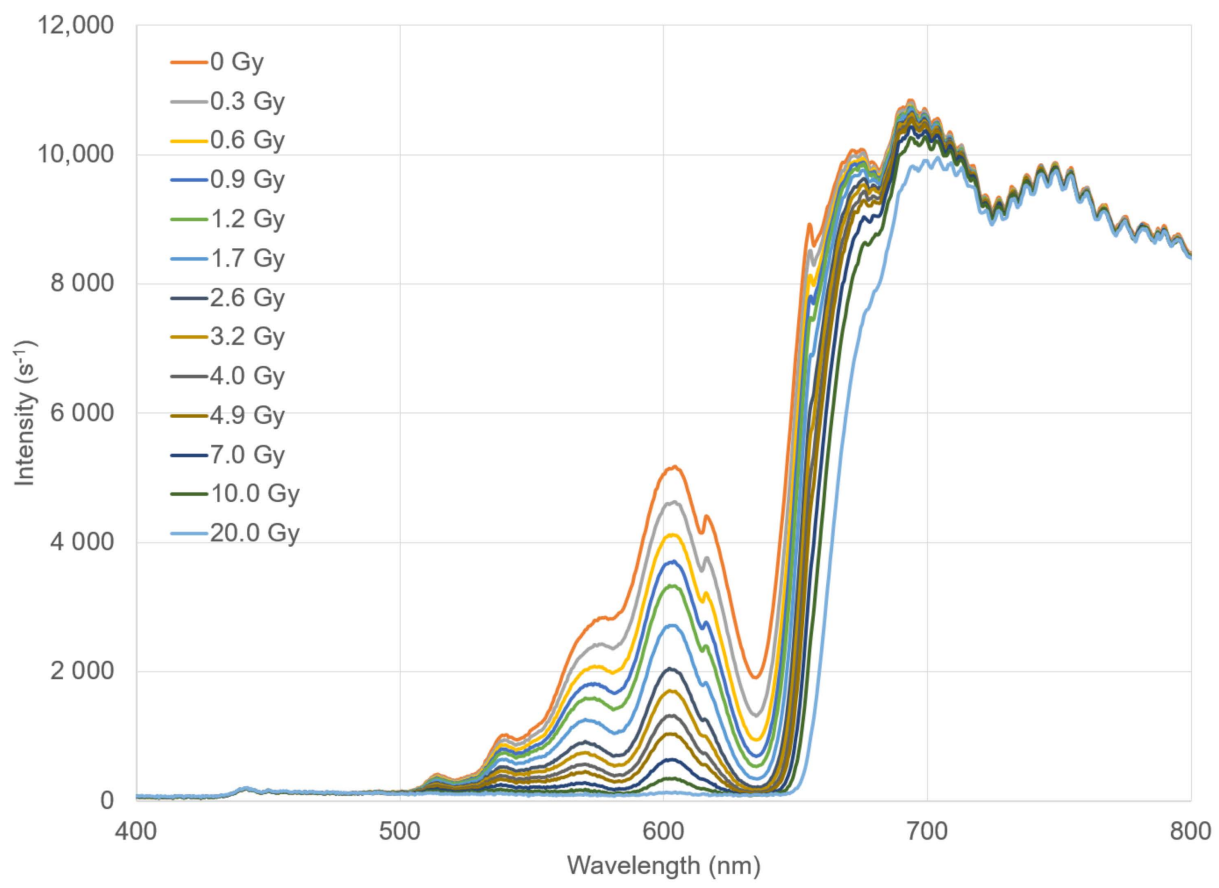

Figure 6. Spectral response of EBT3 (EBT = External Beam Therapy) Gafchromic ${ }^{\mathrm{TM}}$ films exposed to doses in the range 0-20 Gy. Adapted from Reference [86].

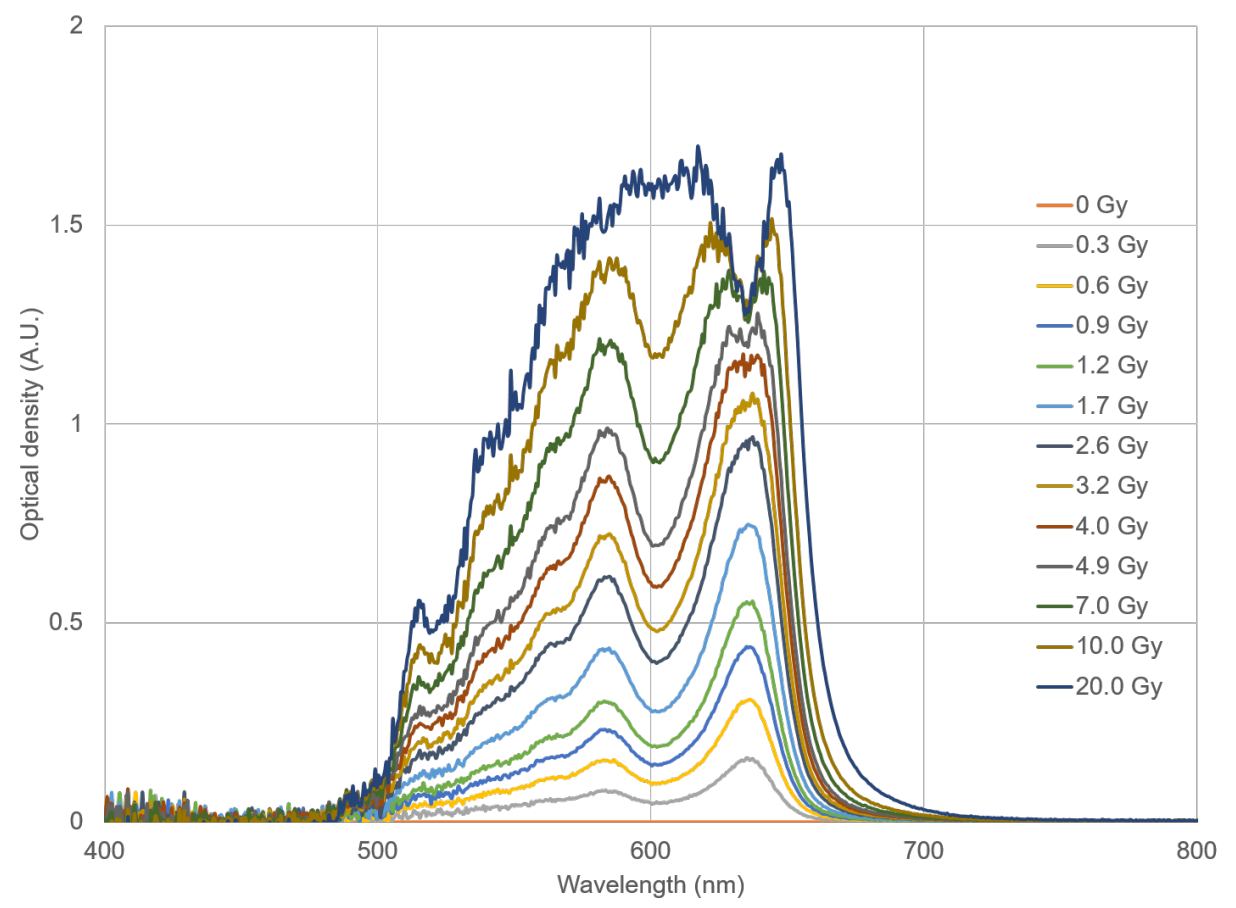

Figure 7. Spectral response (in optical density) of EBT3 Gafchromic ${ }^{\mathrm{TM}}$ films exposed to doses in the range $0-20 \mathrm{~Gy}$. 


\section{Radiochromic Films Response to Relevant Physical Quantities}

Ionizing radiation induce the polymerization process into the $\mathrm{RCF}^{\prime} \mathrm{s}$ active layer. As a consequence of this, RCFs are sensitive to almost all types of ionizing radiation and have therefore been used in photon, electron, proton, and heavy ion radiation environment in different dose ranges. Several works carried out to study the RCF dose rate dependence confirmed that RCFs can be considered dose rate independent over a wide dose range $[89,100,101]$. Bin et al. reported on absolute calibration measurements for HD-V2 Gafchromic $^{\mathrm{TM}}$ films in extremely high dose rate, approaching $7 \times 10^{11} \mathrm{~Gy} / \mathrm{s}$, for laserdriven ion beams [102]. RCF radiation type and energy dependence has been deeply investigated over the last few years mainly for the RCF types used in medical dosimetry, such as Gafchromic ${ }^{\mathrm{TM}}$ EBT series and XRQA-2. The dose response of EBT-3 Gafchromic ${ }^{\mathrm{TM}}$ films is very weakly (less than 1\%) dependent on photon and electron energies of clinical interest $(6-16 \mathrm{MeV})$, as well as on ${ }^{60} \mathrm{Co}$ gamma rays, while, at very low x-ray energies $(50 \mathrm{keV})$, the energy dependence is observed $[9,103,104]$. EBT-3 films show an under response at energies less than $100 \mathrm{keV}$ and this under response increases as the energy decreases $[105,106]$. Bekerat et al. suggested that the energy dependence can be improved by modifying the chemical composition of the active element [105]. For charged particles, the energy dependence is more complicated. The dose $D$ for a charged particle of kinetic energy $E$ is given by:

$$
D=K \times(S / \rho)_{E} \times \Phi,
$$

where $\Phi$ is the fluence in $\mathrm{cm}^{-2} ; S / \rho$ is the mass stopping power, expressed in $\mathrm{MeV} \times \mathrm{cm}^{2} \mathrm{~g}^{-1}$, and it is evaluated for the reference material (water for medical applications) at the energy $E$; and $K=1.6 \times 10^{-10}$ is a conversion factor to express the dose in Gy. EBT-3 Gafchromic ${ }^{\mathrm{TM}}$ film's response to protons in the energy range $63-230 \mathrm{MeV}$ has been observed to be not different from that of photons, within the uncertainties [37]. The response to low energy high LET charged particles, namely in the proximity of the Bragg peak, is characterized by a significant dose under response, also referred to as quenching effect. It is useful, as well as interesting, to understand the energy and LET range for which the quenching effect is observed. An analysis on the data from the referred works suggests that quenching effects for EBT series films exposed to protons are observed from about $5 \mathrm{MeV}\left(79 \mathrm{MeV} \times \mathrm{cm}^{2} \mathrm{~g}^{-1}\right)$. Indeed, Vallières et al. observed the same calibration curves (within experimental uncertainty) for 7 and $10 \mathrm{MeV}$ protons, and that these curves correspond to the one proposed by Khachonkham et al. for $148.2 \mathrm{MeV}$ protons $[107,108]$. The same calibration curve for EBT3 films exposed to 23, 50, and $200 \mathrm{MeV}$ protons, as well as to low LET radiations, such as ${ }^{60} \mathrm{Co}$ gamma rays, was found by Campajola et al. [53]. Quenching effects have been observed for $4 \mathrm{MeV}\left(94 \mathrm{MeV} \times \mathrm{cm}^{2} \mathrm{~g}^{-1}\right)$, as well as $5 \mathrm{MeV}$ protons $[109,110]$. Overall EBT-3 films response to high energy and low $\mathrm{dE} / \mathrm{dx}$ (far from the Bragg peak) protons has proved to have weak energy dependence over a wide energy range and that it is comparable to that to gamma radiation. This implies that it is possible to use the same calibration, within experimental uncertainties, for EBT-3 films (from the same batch) to high energy and low LET protons and to gamma rays of the energy of, e.g., ${ }^{60} \mathrm{Co}$. EBT-XD film response features similar characteristics as that of EBT-3 films both to photon and proton radiation [108]. Gafchromic ${ }^{\mathrm{TM}}$ film models used in diagnostic applications, such as XRQA-2 Gafchromic ${ }^{\mathrm{TM}}$ films, have been observed to have a significant dependence on photon energies which are typical of $\mathrm{x}$-ray radiology diagnostics [111]. HD-V2 Gafchromic ${ }^{\mathrm{TM}}$ films feature a different structure from the EBT series Gafchromic ${ }^{\mathrm{TM}}$ films. The response of these RCFs to more than one radiation type has been recently evaluated for their proven use as detectors for profile measurement of low energy ion beams [112], as well as for laser accelerated proton beams [113]. While their response to low energy protons has been seen to be independent on the energy in the range $2-10 \mathrm{MeV}$ [113], their response results to be strongly LET dependent $[112,114,115]$. It should be noted that HD-V2 Gafchromic ${ }^{\mathrm{TM}}$ films have a different structure from the other Gafchromic ${ }^{\mathrm{TM}}$ films as they feature a $12 \mu \mathrm{m}$ thin active layer on a $97 \mu \mathrm{m}$ polyester substrate. The LET dependence is common to other types 
of dosimeters; however, recently developed nanocomposite Fricke gel dosimeters have shown to have no dependence on the LET in a wide LET range [116,117].

\section{Conclusions and Outlook}

This review paper summarizes the main aspects on radiochromic films for twodimensional dose distribution measurements. The structure, dynamics and spatial resolution of selected RCF types is reported in order to shed a light on their high dynamic range and spatial resolution. This definitely results in their widespread use, particularly in medical applications. Features less than 25 micrometers can be resolved, although specific measurements of the RCF's spatial resolution would add important information. The use of flatbed scanner is advantageous and widespread in medical applications. However, their use is not trivial, as it is demonstrated by the high number of works on this topic, and it demands strict adherence to RCF protocols, as well as deep knowledge of the subject. Main sources of uncertainty are the lateral scanning effects and the warm-up of the scanner, as well as the dependence on the orientation of the film on the flatbed scanner. Changes of environmental conditions, such as the temperature, humidity, exposure to UV light, etc., affect the RCF reading and should be considered, as well. The available technical options for flatbed-scanner-based RCF dosimetry allow the achievement of a predefined degree of precision, with overall measurement uncertainty up to about $2 \%$. Densitometers are easy-to-use and provide direct measurement of the optical density at a fixed wavelength or in a fixed wavelength range. The spectral response of RCFs introduces an important feature in the RCF analysis. Indeed, a careful wavelength study allows to select parts of the spectrum of different sensitivity to radiation-induced changes on the film. This has been proved helpful in order to use some RCF types in non-standard conditions of dynamics and sensitivity. RCF's dependence on the energy is overall weak. However, care should be taken in particular when dealing with charged particle beams, where RCFs have proved to have a significant under-response, also referred to as quenching effect, which should not be ignored for measurements in the Bragg peak region. RCFs have found wide applicability as beam profile detectors in charged particle accelerators and have been found to be particularly suited for applications in high dose rate particle beams, such as the laser-driven accelerators. This study pointed out these key aspects in RCF measurements in order to provide the reader with a concise updated summary on the topic.

Funding: This work was partially funded by the Swiss National Science Foundation (SNSF) (Grant CRSII5_180352).

Institutional Review Board Statement: Not applicable.

Informed Consent Statement: Not applicable.

Data Availability Statement: The data presented in this study are available on request from the corresponding author.

Acknowledgments: I would like to sincerely thank Saverio Braccini for supporting me in this work, as well as for useful discussions. I also would like to thank my colleagues of the Group of Medical Applications of Particle Physics at LHEP; in particular, I would like to thank Philipp Häffner for the help provided in reviewing the manuscript.

Conflicts of Interest: The author declare no conflict of interest.

\section{References}

1. Braccini, S. The new Bern PET cyclotron, its research beam line, and the development of an innovative beam monitor detector. In AIP Conference Proceedings; American Institute of Physics: New York, NY, USA, 2013; Volume 1525, pp. 144-150.

2. Braccini, S. Particle accelerators and detectors for medical diagnostics and therapy. arXiv 2016, arXiv:1601.06820.

3. Belver-Aguilar, C.; Braccini, S.; Carzaniga, T.S.; Gsponer, A.; Häffner, P.D.; Scampoli, P.; Schmidt, M. A Novel Three-Dimensional Non-Destructive Beam-Monitoring Detector. Appl. Sci. 2020, 10, 8217. [CrossRef] 
4. Tommasino, F.; Rovituso, M.; Fabiano, S.; Piffer, S.; Manea, C.; Lorentini, S.; Lanzone, S.; Wang, Z.; Pasini, M.; Burger, W.; et al. Proton beam characterization in the experimental room of the Trento Proton Therapy facility. Nucl. Instrum. Methods Phys. Res. Sect. Accel. Spectrometers Detect. Assoc. Equip. 2017, 869, 15-20. [CrossRef]

5. Auger, M.; Braccini, S.; Carzaniga, T.S.; Ereditato, A.; Nesteruk, K.P.; Scampoli, P. A detector based on silica fibers for ion beam monitoring in a wide current range. J. Instrum. 2016, 11, P03027. [CrossRef]

6. Hoehr, C.; Hanna, M.; Zeisler, S.; Penner, C.; Stokely, M.; Dehnel, M. Ce-and B-Doped Silica Fibers for Monitoring Low-Energy Proton Beams on a Medical Cyclotron. Appl. Sci. 2020, 10, 4488. [CrossRef]

7. Potkins, D.E.; Braccini, S.; Nesteruk, K.P.; Carzaniga, T.S.; Vedda, A.; Chiodini, N.; Timmermans, J.; Melanson, S.; Dehnel, M.P. A low-cost beam profiler based on cerium-doped silica fibers. Phys. Procedia 2017, 90, 215-222. [CrossRef]

8. Gambarini, G.; Regazzoni, V.; Artuso, E.; Giove, D.; Mirandola, A.; Ciocca, M. Measurements of 2D distributions of absorbed dose in protontherapy with Gafchromic EBT3 films. Appl. Radiat. Isot. 2015, 104, 192-196. [CrossRef] [PubMed]

9. Sipilä, P.; Ojala, J.; Kaijaluoto, S.; Jokelainen, I.; Kosunen, A. Gafchromic EBT3 film dosimetry in electron beams-energy dependence and improved film read-out. J. Appl. Clin. Med. Phys. 2016, 17, 360-373. [CrossRef]

10. Borca, V.C.; Pasquino, M.; Russo, G.; Grosso, P.; Cante, D.; Sciacero, P.; Girelli, G.; Porta, M.R.L.; Tofani, S. Dosimetric characterization and use of GAFCHROMIC EBT3 film for IMRT dose verification. J. Appl. Clin. Med. Phys. 2013, 14, 158-171. [CrossRef] [PubMed]

11. Nobah, A.; Aldelaijan, S.; Devic, S.; Tomic, N.; Seuntjens, J.; Al-Shabanah, M.; Moftah, B. Radiochromic film based dosimetry of image-guidance procedures on different radiotherapy modalities. J. Appl. Clin. Med. Phys. 2014, 15, 229-239. [CrossRef]

12. Das, I.J. Radiochromic Film: Role and Applications in Radiation Dosimetry; CRC Press: Boca Raton, FL, USA, 2017.

13. Niroomand-Rad, A.; Blackwell, C.R.; Coursey, B.M.; Gall, K.P.; Galvin, J.M.; McLaughlin, W.L.; Meigooni, A.S.; Nath, R.; Rodgers, J.E.; Soares, C.G. Radiochromic film dosimetry: Recommendations of AAPM radiation therapy committee task group 55. Med. Phys. 1998, 25, 2093-2115. [CrossRef] [PubMed]

14. Devic, S. Radiochromic film dosimetry: Past, present, and future. Phys. Med. 2011, 27, 122-134. [CrossRef]

15. Butson, M.J.; Peter, K.; Cheung, T.; Metcalfe, P. Radiochromic film for medical radiation dosimetry. Mater. Sci. Eng. R Rep. 2003, 41, 61-120. [CrossRef]

16. Devic, S.; Tomic, N.; Lewis, D. Reference radiochromic film dosimetry: Review of technical aspects. Phys. Med. 2016, 32, 541-556. [CrossRef] [PubMed]

17. Williams, M.; Metcalfe, P. Radiochromic film dosimetry and its applications in radiotherapy. In AIP Conference Proceedings; American Institute of Physics: New York, NY, USA, 2011; Volume 1345, pp. 75-99.

18. Santos, T.; Ventura, T.; Lopes, M.D.C. A review on radiochromic film dosimetry for dose verification in high energy photon beams. Radiat. Phys. Chem. 2021, 179, 109217. [CrossRef]

19. McLaughlin, W.; Humphreys, J.; Hocken, D.; Chappas, W. Radiochromic dosimetry for validation and commissioning of industrial radiation processes. Int. J. Radiat. Appl. Instrum. Part C. Radiat. Phys. Chem. 1988, 31, 505-514. [CrossRef]

20. McLaughlin, W.L.; Yun-Dong, C.; Soares, C.G.; Miller, A.; Van Dyk, G.; Lewis, D.F. Sensitometry of the response of a new radiochromic film dosimeter to gamma radiation and electron beams. Nucl. Instrum. Methods Phys. Res. Sect. A Accel. Spectrometers Detect. Assoc. Equip. 1991, 302, 165-176. [CrossRef]

21. McLaughlin, W.L.; Puhl, J.M.; Al-Sheikhly, M.; Christou, C.; Miller, A.; Kovacs, A.; Wojnarovits, L.; Lewis, D.F. Novel radiochromic films for clinical dosimetry. Radiat. Prot. Dosim. 1996, 66, 263-268. [CrossRef]

22. Meigooni, A.S.; Sanders, M.; Ibbott, G.; Szeglin, S. Dosimetric characteristics of an improved radiochromic film. Med. Phys. 1996, 23, 1883-1888. [CrossRef]

23. Tomic, N.; Devic, S. Radiochromic Film Dosimetry for Radiology. In Handbook of X-ray Imaging: Physics and Technology; CRC Press: Boca Raton, FL, USA, 2017; p. 203.

24. Fiandra, C.; Ricardi, U.; Ragona, R.; Anglesio, S.; Romana Giglioli, F.; Calamia, E.; Lucio, F. Clinical use of EBT model Gafchromic ${ }^{\mathrm{TM}}$ film in radiotherapy. Med. Phys. 2006, 33, 4314-4319. [CrossRef]

25. Asgharizadeh, S.; Bekerat, H.; Syme, A.; Aldelaijan, S.; DeBlois, F.; Vuong, T.; Evans, M.; Seuntjens, J.; Devic, S. Radiochromic film-based quality assurance for CT-based high-dose-rate brachytherapy. Brachytherapy 2015, 14, 578-585. [CrossRef] [PubMed]

26. Gafar, S.; El-Ahdal, M. A new developed radiochromic film for high-dose dosimetry applications. Dyes Pigment. 2015, 114, 273-277. [CrossRef]

27. Di Capua, F.; Campajola, L.; Casolaro, P.; Campajola, M.; Aloisio, A.; Lucaroni, A.; Furano, G.; Menicucci, A.; Di Mascio, S.; Malatesta, F; et al. Full characterization of a compact 90Sr/90Y beta source for TID radiation testing. Adv. Space Res. 2019, 63, 3249-3257. [CrossRef]

28. Menicucci, A.; Malatesta, F.; Di Capua, F.; Campajola, L.; Casolaro, P.; Furano, G.; Di Mascio, S.; Ottavi, M. Simplified Procedures for COTS TID Testing: A Comparison Between 90 Sr and 60 Co. In Proceedings of the 2018 IEEE Radiation Effects Data Workshop (REDW), Waikoloa Village, HI, USA, 16-20 July 2018; pp. 1-6.

29. Martorana, F.; Parlato, A.; Perrone, G.; Tomarchio, E.A.G. Response of GAFChromic ${ }^{\circledR}$ HD-V2 film dosimeter in 10-300 Gy dose range for radiation testing of electronic devices. Nucl. Technol. Radiat. Prot. 2019, 34, 79-84. [CrossRef]

30. Ravotti, F. Dosimetry techniques and radiation test facilities for total ionizing dose testing. IEEE Trans. Nucl. Sci. 2018, 65, 1440-1464. [CrossRef] 
31. Anders, J.; Braccini, S.; Carzaniga, T.; Ereditato, A.; Fehr, A.; Meloni, F.; Merlassino, C.; Miucci, A.; Rimoldi, M.; Weber, M. A facility for radiation hardness studies based on the Bern medical cyclotron. arXiv 2018, arXiv:1803.01939.

32. Aldelaijan, S.; Nobah, A.; Alsbeih, G.; Moftah, B.; Aldahlawi, I.; Alzahrany, A.; Tomic, N.; Devic, S. Dosimetry of biological irradiations using radiochromic films. Phys. Med. Biol. 2013, 58, 3177. [CrossRef]

33. Baratto-Roldán, A.; Jiménez-Ramos, M.D.C.; Battaglia, M.C.; García-López, J.; Gallardo, M.I.; Cortés-Giraldo, M.A.; Espino, J.M. Feasibility study of a proton irradiation facility for radiobiological measurements at an $18 \mathrm{MeV}$ cyclotron. Instruments 2018, 2, 26. [CrossRef]

34. del Río, J.T.; Forastero, C.; Moreno-Torres, M.; Molina-Matas, M.; Martínez-Felipe, A.M.; Moreno, Á.; López-Peñalver, J.J.; Guirado, D. Use of radiochromic film dosimetry in radiobiology experiments. Radiat. Phys. Chem. 2019, 156, 169-173. [CrossRef]

35. Ghithan, S.; Crespo, P.; do Carmo, S.; Marques, R.F.; Fraga, F.; Simões, H.; Alves, F.; Rachinhas, P. Development of a PET cyclotron based irradiation setup for proton radiobiology. J. Instrum. 2015, 10, P02010. [CrossRef]

36. Krzempek, D.; Mianowska, G.; Bassler, N.; Stolarczyk, L.; Kopeć, R.; Sas-Korczyńska, B.; Olko, P. Calibration of Gafchromic EBT3 film for dosimetry of scanning proton pencil beam (PBS). Radiat. Prot. Dosim. 2018, 180, 324-328. [CrossRef] [PubMed]

37. Castriconi, R.; Ciocca, M.; Mirandola, A.; Sini, C.; Broggi, S.; Schwarz, M.; Fracchiolla, F.; Martišíková, M.; Aricò, G.; Mettivier, G.; et al. Dose-response of EBT3 radiochromic films to proton and carbon ion clinical beams. Phys. Med. Biol. 2016, 62, 377. [CrossRef] [PubMed]

38. Yonai, S.; Arai, C.; Shimoyama, K.; Fournier-Bidoz, N. Experimental evaluation of dosimetric characterization of gafchromic EBT3 and EBT-XD films for clinical carbon ion beams. Radiat. Prot. Dosim. 2018, 180, 314-318. [CrossRef]

39. Hara, Y.; Furukawa, T.; Mizushima, K.; Takeshita, E.; Shirai, T.; Noda, K. Application of radiochromic film for quality assurance in the heavy-ion beam scanning irradiation system at HIMAC. Nucl. Instrum. Methods Phys. Res. Sect. B Beam Interact. Mater. Atoms 2014, 331, 253-256. [CrossRef]

40. Avila-Rodriguez, M.; Wilson, J.; McQuarrie, S. The use of radiochromic films to measure and analyze the beam profile of charged particle accelerators. Appl. Radiat. Isot. 2009, 67, 2025-2028. [CrossRef] [PubMed]

41. Sansaloni, F.; Lagares, J.; Arce, P.; Llop, J.; Perez, J. Characterization of the proton beam from an IBA Cyclone 18/9 with radiochromic film EBT2. In AIP Conference Proceedings; American Institute of Physics: New York, NY, USA, 2012; Volume 1509, pp. $46-50$.

42. Braccini, S.; Ereditato, A.; Scampoli, P.; von Bremen, K. The new Bern cyclotron laboratory for radioisotope production and research. In Proceedings of the Second International Particle Accelerator Conference-IPAC2011 (3618), San Sebastian, Spain, 4-9 September 2011.

43. Lasi, D.; Tulej, M.; Neuland, M.B.; Wurz, P.; Carzaniga, T.S.; Nesteruk, K.P.; Braccini, S.; Elsener, H. Testing the radiation hardness of thick-film resistors for a time-of-flight mass spectrometer at jupiter with $18 \mathrm{MeV}$ protons. In Proceedings of the 2017 IEEE Radiation Effects Data Workshop (REDW), New Orleans, LA, USA, 17-21 July 2017; pp. 1-9.

44. Nürnberg, F.; Schollmeier, M.; Brambrink, E.; Blažević, A.; Carroll, D.; Flippo, K.; Gautier, D.; Geissel, M.; Harres, K.; Hegelich, B.; et al. Radiochromic film imaging spectroscopy of laser-accelerated proton beams. Rev. Sci. Instrum. 2009, 80, 033301. [CrossRef]

45. Kaufman, J.; Margarone, D.; Candiano, G.; Kim, I.J.; Jeong, T.M.; Pšikal, J.; Romano, F.; Cirrone, P.; Scuderi, V.; Korn, G. Radiochromic film diagnostics for laser-driven ion beams. In Research Using Extreme Light: Entering New Frontiers with PetawattClass Lasers II; International Society for Optics and Photonics: San Diego, CA, USA, 2015; Volume 9515, p. 95151J.

46. Cirrone, G.; Petringa, G.; Cagni, B.; Cuttone, G.; Fustaino, G.; Guarrera, M.; Khanna, R.; Catalano, R. Use of radiochromic films for the absolute dose evaluation in high dose-rate proton beams. J. Instrum. 2020, 15, C04029. [CrossRef]

47. Ashraf, M.R.; Rahman, M.; Zhang, R.; Williams, B.B.; Gladstone, D.J.; Pogue, B.W.; Bruza, P. Dosimetry for FLASH Radiotherapy: A Review of Tools and the Role of Radioluminescence and Cherenkov Emission. arXiv 2020, arXiv:2006.03755.

48. Curry, C.; Dunning, C.; Gauthier, M.; Chou, H.G.; Fiuza, F.; Glenn, G.; Tsui, Y.; Bazalova-Carter, M.; Glenzer, S. Optimization of radiochromic film stacks to diagnose high-flux laser-accelerated proton beams. Rev. Sci. Instrum. 2020, 91, 093303. [CrossRef]

49. Butson, M.; Niroomand-Rad, A. Historical background, development, and construction of radiochromic films. In Radiochromic Film: Role and Applications in Radiation Dosimetry; CRC Press: Boca Raton, FL, USA, 2017.

50. McLaughlin, W. A radiochromic solid-state polymerization reaction. In Proceedings of the 208th ACS National Meeting, Washington, DC, USA, 21-26 August 1994.

51. McLaughlin, W.L.; Al-Sheikhly, M.; Lewis, D.; Kovács, A.; Wojnárovits, L. Radiochromic Solid-State Polymerization Reaction; ACS Publications: Washington, DC, USA, 1996.

52. Cheung, T.; Butson, M.J.; Peter, K. Post-irradiation colouration of Gafchromic EBT radiochromic film. Phys. Med. Biol. 2005, 50, N281. [CrossRef]

53. Campajola, L.; Casolaro, P.; Di Capua, F. Absolute dose calibration of EBT3 Gafchromic films. J. Instrum. 2017, 12, P08015. [CrossRef]

54. Labate, L.; Lamia, D.; Russo, G. Dosimetry of laser-driven electron beams for radiobiology and medicine. In Laser-Driven Particle Acceleration towards Radiobiology and Medicine; Springer: Berlin/Heidelberg, Germany, 2016; pp. 203-218.

55. McCabe, B.P.; Speidel, M.A.; Pike, T.L.; Van Lysel, M.S. Calibration of GafChromic XR-RV3 radiochromic film for skin dose measurement using standardized x-ray spectra and a commercial flatbed scanner. Med. Phys. 2011, 38, 1919-1930. [CrossRef]

56. Al-Okshi, A.; Nilsson, M.; Petersson, A.; Wiese, M.; Lindh, C. Using GafChromic film to estimate the effective dose from dental cone beam CT and panoramic radiography. Dentomaxillofacial Radiol. 2013, 42, 20120343. [CrossRef] [PubMed] 
57. Miura, H.; Ozawa, S.; Hosono, F.; Sumida, N.; Okazue, T.; Yamada, K.; Nagata, Y. Gafchromic EBT-XD film: Dosimetry characterization in high-dose, volumetric-modulated arc therapy. J. Appl. Clin. Med. Phys. 2016, 17, 312-322. [CrossRef] [PubMed]

58. Miller, A.; Batsberg, W.; Karman, W. A new radiochromic thin-film dosimeter system. Int. J. Radiat. Appl. Instrum. Part C. Radiat. Phys. Chem. 1988, 31, 491-496. [CrossRef]

59. Butson, M.J.; Cheung, T.; Peter, K. Absorption spectra analysis of exposed FWT-60 radiochromic film. Phys. Med. Biol. 2004, 49, N377. [CrossRef]

60. Ashland ${ }^{\mathrm{TM}}$. Gafchromic Films. 2021. Available online: http://www.gafchromic.com/gafchromic-film/radiotherapy-films/HDV2/index.asp (accessed on 10 February 2021).

61. Fusi, F.; Mercatelli, L.; Marconi, G.; Cuttone, G.; Romano, G. Optical characterization of a radiochromic film by total reflectance and transmittance measurements. Med. Phys. 2004, 31, 2147-2154. [CrossRef]

62. Aldelaijan, S.; Devic, S. Comparison of dose response functions for EBT3 model GafChromic ${ }^{\mathrm{TM}}$ film dosimetry system. Phys. Med. 2018, 49, 112-118. [CrossRef]

63. Butson, M.J.; Peter, K.; Cheung, T.; Inwood, D. Polarization effects on a high-sensitivity radiochromic film. Phys. Med. Biol. 2003, 48, N207. [CrossRef]

64. Andres, C.; Del Castillo, A.; Tortosa, R.; Alonso, D.; Barquero, R. A comprehensive study of the Gafchromic EBT2 radiochromic film. A comparison with EBT. Med. Phys. 2010, 37, 6271-6278. [CrossRef]

65. Butson, E.T.; Cheung, T.; Peter, K.; Butson, M.J. Measuring solar UV radiation with EBT radiochromic film. Phys. Med. Biol. 2010, 55, N487. [CrossRef]

66. García-Garduño, O.A.; Lárraga-Gutiérrez, J.M.; Rodríguez-Villafuerte, M.; Martínez-Dávalos, A.; Celis, M.A. Small photon beam measurements using radiochromic film and Monte Carlo simulations in a water phantom. Radiother. Oncol. 2010, 96, 250-253. [CrossRef]

67. Severgnini, M.; de Denaro, M.; Bortul, M.; Vidali, C.; Beorchia, A. In vivo dosimetry and shielding disk alignment verification by EBT3 GAFCHROMIC film in breast IOERT treatment. J. Appl. Clin. Med. Phys. 2015, 16, 112-120. [CrossRef]

68. León-Marroquín, E.Y.; Lárraga-Gutiérrez, J.M.; Herrera-González, J.A.; Camacho-López, M.A.; Villarreal Barajas, J.E.; GarcíaGarduño, O.A. Investigation of EBT 3 radiochromic film's response to humidity. J. Appl. Clin. Med. Phys. 2018, 19, 283-290. [CrossRef]

69. Aldelaijan, S.; Alzorkany, F.; Moftah, B.; Buzurovic, I.; Seuntjens, J.; Tomic, N.; Devic, S. Use of a control film piece in radiochromic film dosimetry. Phys. Med. 2016, 32, 202-207. [CrossRef]

70. Ferreira, B.; Lopes, M.; Capela, M. Evaluation of an Epson flatbed scanner to read Gafchromic EBT films for radiation dosimetry. Phys. Med. Biol. 2009, 54, 1073. [CrossRef]

71. Lárraga-Gutiérrez, J.M.; García-Garduño, O.A.; Treviño-Palacios, C.; Herrera-González, J.A. Evaluation of an LED-based flatbed document scanner for radiochromic film dosimetry in transmission mode. Phys. Med. 2018, 47, 86-91. [CrossRef]

72. Schoenfeld, A.A.; Wieker, S.; Harder, D.; Poppe, B. The origin of the flatbed scanner artifacts in radiochromic film dosimetry-Key experiments and theoretical descriptions. Phys. Med. Biol. 2016, 61, 7704. [CrossRef] [PubMed]

73. Schoenfeld, A.A.; Poppinga, D.; Harder, D.; Doerner, K.J.; Poppe, B. The artefacts of radiochromic film dosimetry with flatbed scanners and their causation by light scattering from radiation-induced polymers. Phys. Med. Biol. 2014, 59, 3575. [CrossRef] [PubMed]

74. Van Battum, L.; Huizenga, H.; Verdaasdonk, R.; Heukelom, S. How flatbed scanners upset accurate film dosimetry. Phys. Med. Biol. 2015, 61, 625. [CrossRef] [PubMed]

75. Lewis, D.; Chan, M.F. Correcting lateral response artifacts from flatbed scanners for radiochromic film dosimetry. Med. Phys. 2015, 42, 416-429. [CrossRef]

76. Micke, A.; Lewis, D.F.; Yu, X. Multichannel film dosimetry with nonuniformity correction. Med. Phys. 2011, 38, 2523-2534. [CrossRef] [PubMed]

77. Lewis, D.; Micke, A.; Yu, X.; Chan, M.F. An efficient protocol for radiochromic film dosimetry combining calibration and measurement in a single scan. Med. Phys. 2012, 39, 6339-6350. [CrossRef] [PubMed]

78. Mathot, M.; Sobczak, S.; Hoornaert, M.T. Gafchromic film dosimetry: Four years experience using FilmQA Pro software and Epson flatbed scanners. Phys. Med. 2014, 30, 871-877. [CrossRef]

79. Marrazzo, L.; Zani, M.; Pallotta, S.; Arilli, C.; Casati, M.; Compagnucci, A.; Talamonti, C.; Bucciolini, M. GafChromic ${ }^{\circledR}$ EBT3 films for patient specific IMRT QA using a multichannel approach. Phys. Med. 2015, 31, 1035-1042. [CrossRef]

80. Howard, M.E.; Herman, M.G.; Grams, M.P. Methodology for radiochromic film analysis using FilmQA Pro and ImageJ. PLoS ONE 2020, 15, e0233562. [CrossRef]

81. Helt-Hansen, J.; Miller, A. RisøScan-A new dosimetry software. Radiat. Phys. Chem. 2004, 71, 361-364. [CrossRef]

82. Helt-Hansen, J.; Miller, A. Assessment of dose measurement uncertainty using RisøScan. Radiat. Phys. Chem. 2006, 75, 1101-1106. [CrossRef]

83. Asero, G.; Greco, C.; Gueli, A.; Raffaele, L.; Spampinato, S. Evaluation of spatial resolution in image acquisition by optical flatbed scanners for radiochromic film dosimetry. J. Instrum. 2016, 11, P03024. [CrossRef]

84. Mirza, J.A.; Hernández Millares, R.; Kim, G.I.; Park, S.Y.; Lee, J.; Ye, S.J. Characterization of radiochromic films as a micrometerresolution dosimeter by confocal Raman spectroscopy. Med. Phys. 2019, 46, 5238-5248. [CrossRef] 
85. Heilemann, G.; Georg, D.; Berg, A. Pushing the boundaries of spatial resolution in dosimetry using polymer gels and radiochromic films. J. Physics Conf. Ser. 2015, 573, 012034. [CrossRef]

86. Casolaro, P. Innovative Detection Methods for Radiation Hardness. Ph.D. Thesis, Università degli Studi di Napoli Federico II, Napoli, Italy, 2019.

87. Devic, S.; Seuntjens, J.; Sham, E.; Podgorsak, E.B.; Schmidtlein, C.R.; Kirov, A.S.; Soares, C.G. Precise radiochromic film dosimetry using a flat-bed document scanner. Med. Phys. 2005, 32, 2245-2253. [CrossRef]

88. Darafsheh, A.; León-Marroquín, E.Y.; Mulrow, D.J.; Baradaran-Ghahfarokhi, M.; Zhao, T.; Khan, R. On the spectral characterization of radiochromic films irradiated with clinical proton beams. Phys. Med. Biol. 2019, 64, 135016. [CrossRef] [PubMed]

89. León-Marroquín, E.Y.; Mulrow, D.J.; Khan, R.; Darafsheh, A. Spectral analysis of the EBT3 radiochromic films for clinical photon and electron beams. Med. Phys. 2019, 46, 973-982. [CrossRef]

90. Martín-Viera Cueto, J.; Parra Osorio, V.; Moreno Sáiz, C.; Navarro Guirado, F.; Casado Villalón, F.; Galán Montenegro, P. A universal dose-response curve for radiochromic films. Med. Phys. 2015, 42, 221-231. [CrossRef]

91. Casolaro, P.; Campajola, L.; Di Capua, F. The physics of radiochromic process: One calibration equation for all film types. J. Instrum. 2019, 14, P08006. [CrossRef]

92. Ibarmia, S.; Eck, J.; Ivanchenko, V.; Lavielle, D.; Rivera, A.; Cueto, J.; Santin, G. Experimental dose enhancement in multi-layer shielding structures exposed to high-energy electron environments. IEEE Trans. Nucl. Sci. 2013, 60, 2486-2493. [CrossRef]

93. Butson, M.J.; Cheung, T.; Yu, P.K.; Alnawaf, H. Dose and absorption spectra response of EBT2 Gafchromic film to high energy X-rays. Australas. Phys. Eng. Sci. Med. 2009, 32, 196-202. [CrossRef] [PubMed]

94. León-Marroquín, E.Y.; Camacho-López, M.A.; García-Garduño, O.A.; Herrera-González, J.A.; Villarreal-Barajas, J.E.; GutiérrezFuentes, R.; Contreras-Bulnes, R. Spectral analysis of the EBT3 radiochromic film irradiated with 6 MV X-ray radiation. Radiat. Meas. 2016, 89, 82-88. [CrossRef]

95. Soares, C.G. New developments in radiochromic film dosimetry. Radiat. Prot. Dosim. 2006, 120, 100-106. [CrossRef]

96. Vaiano, P.; Consales, M.; Casolaro, P.; Campajola, L.; Fienga, F.; Di Capua, F.; Breglio, G.; Buontempo, S.; Cutolo, A.; Cusano, A. A novel method for EBT3 Gafchromic films read-out at high dose levels. Phys. Med. 2019, 61, 77-84. [CrossRef]

97. Casolaro, P.; Campajola, L.; Breglio, G.; Buontempo, S.; Consales, M.; Cusano, A.; Cutolo, A.; Di Capua, F.; Fienga, F.; Vaiano, P. Real-time dosimetry with radiochromic films. Sci. Rep. 2019, 9, 1-11.

98. Mignani, A.G.; Romano, S.; Fusi, F.; Mencaglia, A.A. Radiation dosimetry in radiotherapy: A model for an extrinsic optical fiber sensor. In European Workshop on Optical Fibre Sensors; International Society for Optics and Photonics: San Diego, CA, USA, 1998; Volume 3483, pp. 99-102.

99. Rink, A.; Vitkin, I.A.; Jaffray, D.A. Suitability of radiochromic medium for real-time optical measurements of ionizing radiation dose. Med. Phys. 2005, 32, 1140-1155. [CrossRef]

100. Jaccard, M.; Petersson, K.; Buchillier, T.; Germond, J.F.; Durán, M.T.; Vozenin, M.C.; Bourhis, J.; Bochud, F.O.; Bailat, C. High dose-per-pulse electron beam dosimetry: Usability and dose-rate independence of EBT3 Gafchromic films. Med. Phys. 2017, 44, 725-735. [CrossRef]

101. Karsch, L.; Beyreuther, E.; Burris-Mog, T.; Kraft, S.; Richter, C.; Zeil, K.; Pawelke, J. Dose rate dependence for different dosimeters and detectors: TLD, OSL, EBT films, and diamond detectors. Med. Phys. 2012, 39, 2447-2455. [CrossRef]

102. Bin, J.; Ji, Q.; Seidl, P.; Raftrey, D.; Steinke, S.; Persaud, A.; Nakamura, K.; Gonsalves, A.; Leemans, W.; Schenkel, T. Absolute calibration of GafChromic film for very high flux laser driven ion beams. Rev. Sci. Instrum. 2019, 90, 053301. [CrossRef] [PubMed]

103. Massillon-JL, G.; Chiu-Tsao, S.T.; Domingo-Munoz, I.; Chan, M.F. Energy Dependence of the New Gafchromic EBT3 Film: Dose Response Curves for 50 kV, 6 and 15 MV X-ray Beams. Sci. Res. 2012, 1, 21922.

104. Farah, N.; Francis, Z.; Abboud, M. Analysis of the EBT3 Gafchromic film irradiated with $6 \mathrm{MV}$ photons and $6 \mathrm{MeV}$ electrons using reflective mode scanners. Phys. Med. 2014, 30, 708-712. [CrossRef]

105. Bekerat, H.; Devic, S.; DeBlois, F.; Singh, K.; Sarfehnia, A.; Seuntjens, J.; Shih, S.; Yu, X.; Lewis, D. Improving the energy response of external beam therapy (EBT) GafChromicTM dosimetry films at low energies ( $\leq 100 \mathrm{keV})$. Med. Phys. 2014, $41,022101$. [CrossRef]

106. Hammer, C.G.; Rosen, B.S.; Fagerstrom, J.M.; Culberson, W.S.; DeWerd, L.A. Experimental investigation of GafChromic ${ }^{\circledR}$ EBT3 intrinsic energy dependence with kilovoltage $x$ rays, 137Cs, and 60Co. Med. Phys. 2018, 45, 448-459. [CrossRef]

107. Vallières, S.; Bienvenue, C.; Puyuelo-Valdes, P.; Salvadori, M.; d'Humières, E.; Schiettekatte, F.; Antici, P. Low-energy proton calibration and energy-dependence linearization of EBT-XD radiochromic films. Rev. Sci. Instrum. 2019, 90, 083301. [CrossRef]

108. Khachonkham, S.; Dreindl, R.; Heilemann, G.; Lechner, W.; Fuchs, H.; Palmans, H.; Georg, D.; Kuess, P. Characteristic of EBT-XD and EBT3 radiochromic film dosimetry for photon and proton beams. Phys. Med. Biol. 2018, 63, 065007. [CrossRef]

109. Reinhardt, S.; Würl, M.; Greubel, C.; Humble, N.; Wilkens, J.; Hillbrand, M.; Mairani, A.; Assmann, W.; Parodi, K. Investigation of EBT2 and EBT3 films for proton dosimetry in the 4-20 MeV energy range. Radiat. Environ. Biophys. 2015, 54, 71-79. [CrossRef]

110. Vadrucci, M.; Esposito, G.; Ronsivalle, C.; Cherubini, R.; Marracino, F.; Montereali, R.; Picardi, L.; Piccinini, M.; Pimpinella, M.; Vincenti, M.; et al. Calibration of GafChromic EBT3 for absorbed dose measurements in $5 \mathrm{MeV}$ proton beam and $60 \mathrm{Co} \gamma$-rays. Med. Phys. 2015, 42, 4678-4684. [CrossRef]

111. Di Lillo, F.; Mettivier, G.; Sarno, A.; Tromba, G.; Tomic, N.; Devic, S.; Russo, P. Energy dependent calibration of XR-QA2 radiochromic film with monochromatic and polychromatic x-ray beams. Med. Phys. 2016, 43, 583-588. [CrossRef] 
112. Yuri, Y.; Narumi, K.; Yuyama, T. Characterization of a Gafchromic film for the two-dimensional profile measurement of lowenergy heavy-ion beams. Nucl. Instrum. Methods Phys. Res. Sect. A Accel. Spectrometers Detect. Assoc. Equip. 2016, 828, 15-21. [CrossRef]

113. Xu, X.; Liao, Q.; Wu, M.; Geng, Y.; Li, D.; Zhu, J.; Li, C.; Hu, R.; Shou, Y.; Chen, Y.; et al. Detection and analysis of laser driven proton beams by calibrated Gafchromic HD-V2 and MD-V3 radiochromic films. Rev. Sci. Instrum. 2019, 90, 033306. [CrossRef] [PubMed]

114. Yuri, Y.; Ishizaka, T.; Agematsu, T.; Yuyama, T.; Seito, H.; Okumura, S. Use of a Gafchromic film HD-V2 for the profile measurement of energetic ion beams. Nucl. Instrum. Methods Phys. Res. Sect. B Beam Interact. Mater. Atoms 2017, 406, 221-224. [CrossRef]

115. Torrisi, L.; Havranek, V.; Cutroneo, M.; Torrisi, A. Gafchromic HD-V2 investigations using MeV ion beams in vacuum. Radiat. Eff. Defects Solids 2019, 174, 1063-1075. [CrossRef]

116. Maeyama, T.; Fukunishi, N.; Ishikawa, K.L.; Fukasaku, K.; Fukuda, S. Radiological properties of nanocomposite Fricke gel dosimeters for heavy ion beams. J. Radiat. Res. 2016, 57, 318-324. [CrossRef]

117. Maeyama, T.; Fukunishi, N.; Ishikawa, K.L.; Fukasaku, K.; Fukuda, S. Organic-gelatin-free nanocomposite fricke gel dosimeter. J. Phys. Chem. B 2017, 121, 4238-4246. [CrossRef] [PubMed] 